\title{
Announcement
}

\section{Award of the University of Antwerp}

We are pleased to inform you that our Editorial Board member

\author{
Prof. Dr. J.P.A. Baak
}

Professor of Quantitative Pathology at the Vrije Universiteit, Amsterdam, and Head of the Department of Pathology, Medisch Centrum Alkmaar, The Netherlands, has received from the University of Antwerp, Belgium, the Award of

\section{Doctor Honoris Causa}

because of his international contribution to and development of Quantitative Pathology. The official ceremony took place on 26 May 2000 in the Aula Magna of the University of Antwerp. 


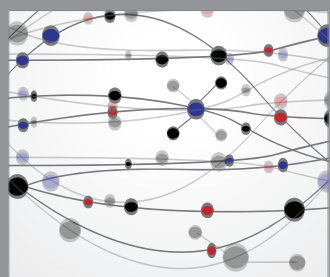

The Scientific World Journal
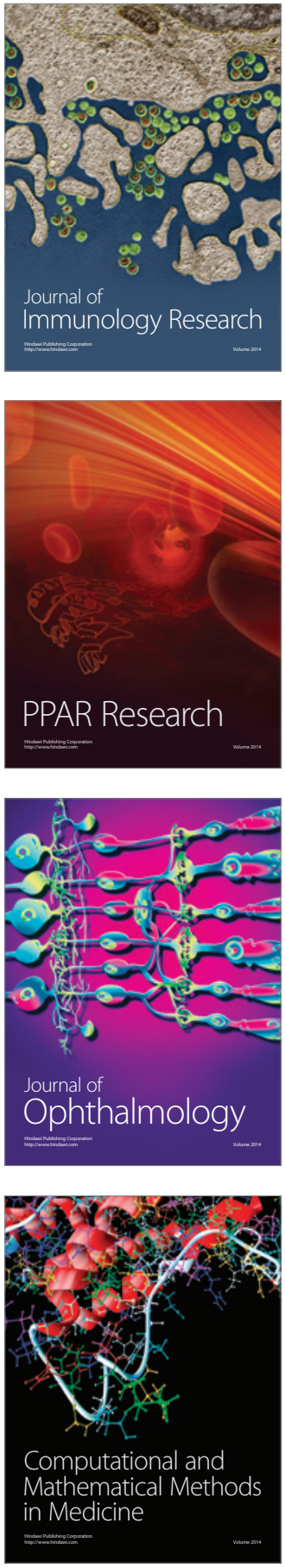

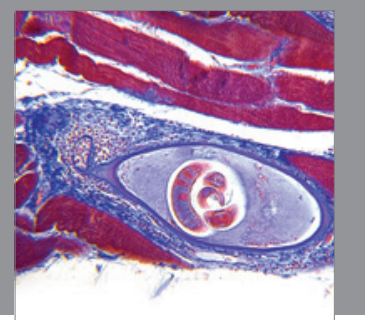

Gastroenterology

Research and Practice
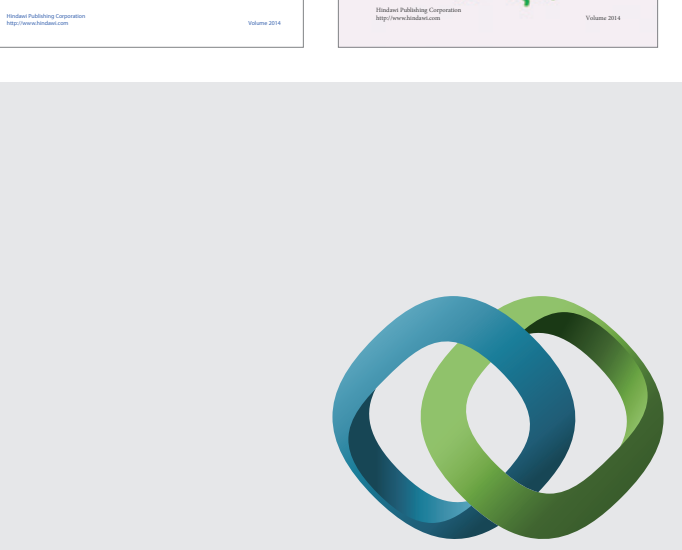

\section{Hindawi}

Submit your manuscripts at

http://www.hindawi.com
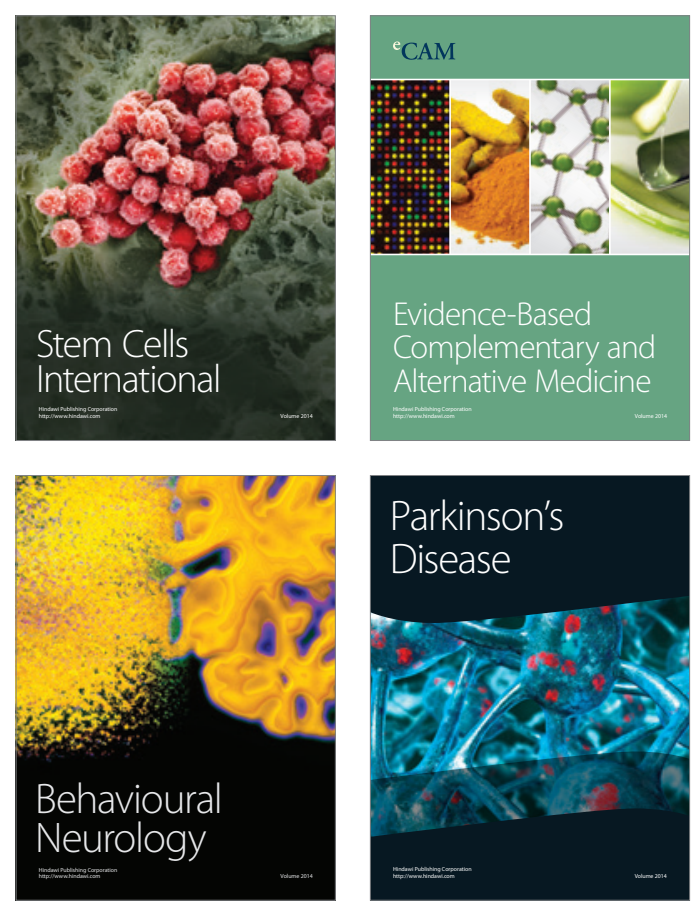

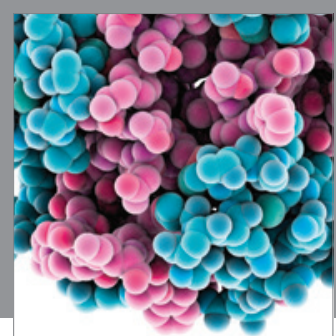

Journal of
Diabetes Research

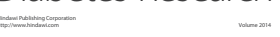

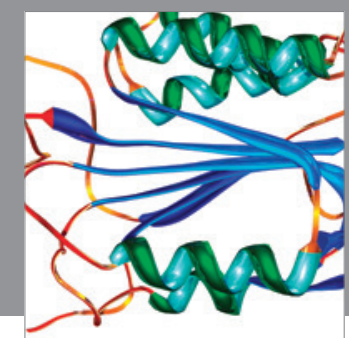

Disease Markers
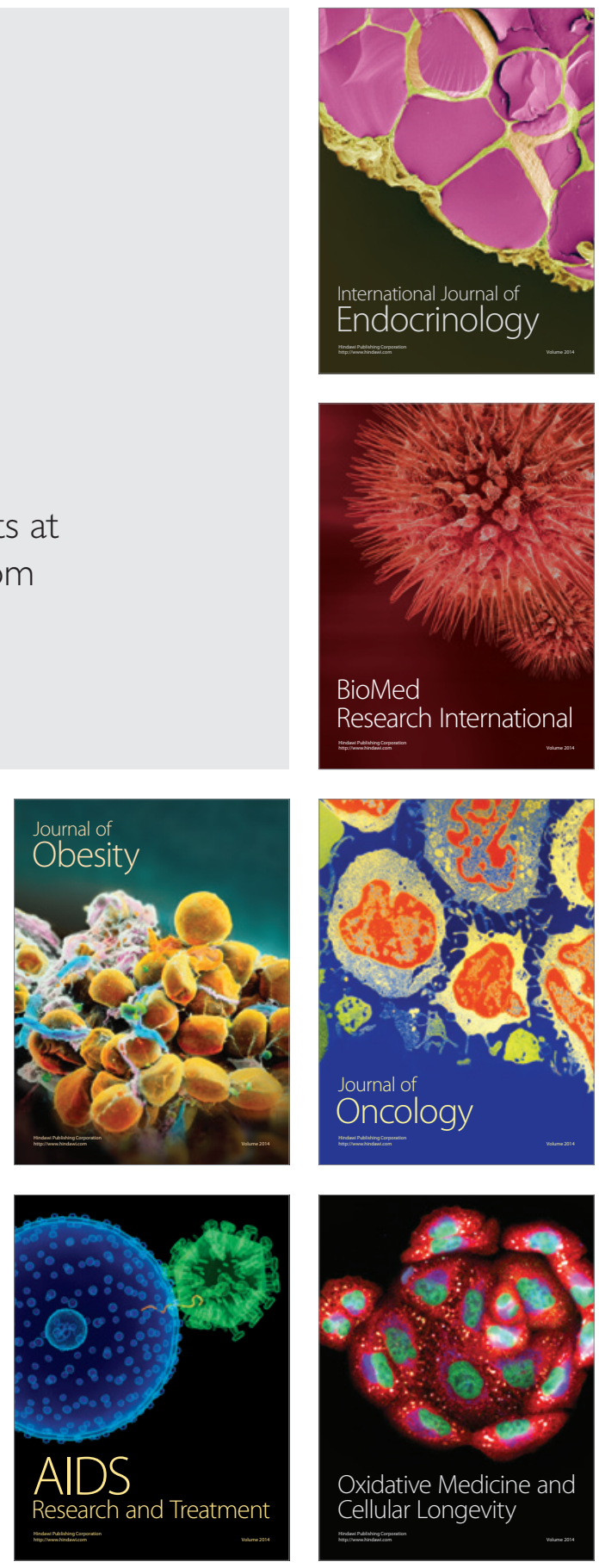